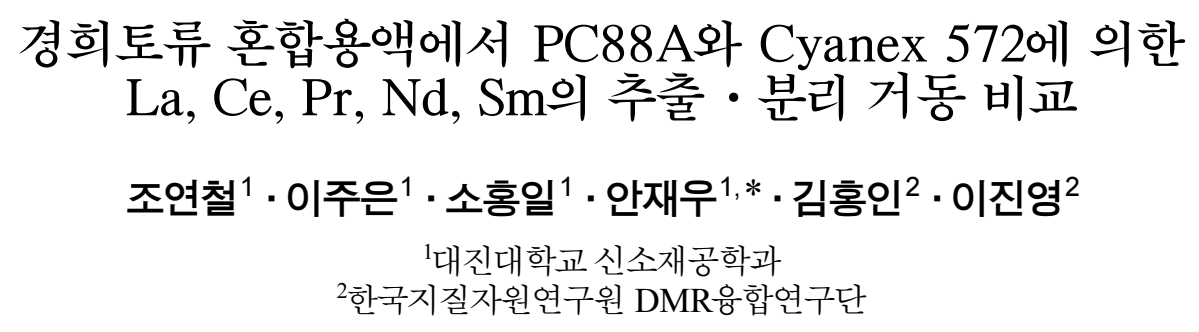

\title{
Comparison of the Extraction and Separation Behavior of La, Ce, Pr, Nd, Sm from Light Rare Earth Mixed Solutions by PC88A and Cyanex 572
}

\author{
Yeon-Chul Cho' ${ }^{1}$, Joo-eun Lee ${ }^{1}$, Hong-Il So ${ }^{1}$, Jae-Woo Ahn',* Hong-in Kim ${ }^{2}$, and Jin-young Lee ${ }^{2}$ \\ ${ }^{1}$ Department of Advanced Materials Science and Engineering, Daejin University, Pocheon 11159, Republic of Korea \\ ${ }^{2}$ Covergence Research Center for Development of Mineral Resources(DMR) Korea Institute \\ of Geoscience and mineral Resources, Daejeon 34132, Republic of Korea
}

\begin{abstract}
Solvent extraction of $\mathrm{La}, \mathrm{Ce}, \mathrm{Pr}, \mathrm{Nd}$ and Sm from chloride solutions was studied using PC88A and Cyanex 572 as the extractants. Our results indicated that the acidity of the aqueous solution and saponification degree had some effect on the percentage extraction of metal ions. The distribution coefficient of the metal ions increased with increasing aqueous solution $\mathrm{pH}$ in both of PC88A and Cyanex 572. But the $\mathrm{pH}_{50}$ value was lowered by about $0.05 \sim 0.34$ in PC88A. In extraction with saponified Cyanex 572 with $\mathrm{NaOH}$, the distribution coefficients of the metal ions were independent of the degree of saponification, and did little to improve the separation behavior of these metal ions. With Cyanex 572 as the extractant, the separation factor of the binary La/Ce and $\mathrm{Nd} / \mathrm{Sm}$ was enhanced about 5.0, but Ce/ $\mathrm{Pr}$ and $\mathrm{Pr} / \mathrm{Nd}$ showed no difference in separation factor as compared with PC88A. The group separation factor of $\mathrm{La} /(\mathrm{Pr}, \mathrm{Nd}, \mathrm{Sm})$ and $(\mathrm{Pr}, \mathrm{Nd}) / \mathrm{Sm}$ was increased by 3.0 8.0, but for $(\mathrm{La}, \mathrm{Ce}) /(\mathrm{Pr}, \mathrm{Nd})$ and $\mathrm{Ce} /$ (Pr, Nd) it was only increased by $0.2 \sim 0.7$ in the Cyanex 572 system.
\end{abstract}

(Received October 18, 2017; Accepted November 15, 2017)

Keywords: rare earth metal, solvent extraction, Cyanex 572, PC88A, separation factor

\section{1. 서 론}

국내 희토류 분류 기준으로 주기율표상에서 제 $3 A$ 족 스 칸듐과 이트륨, 원자번호 57 에서 71 번까지의 란탄계열 총 17원소를 희토류로 분류하고 있다. 희토류 원소는 경(輕)희 토( $\mathrm{La}, \mathrm{Ce}, \mathrm{Pr}, \mathrm{Nd})$, 중(中)희토 $(\mathrm{Sm}, \mathrm{Eu}, \mathrm{Gd}, \mathrm{Tb})$, 중(重) 희토(Dy, Ho, Er, Tm, Lu, Y)로 구분 할 수 있고, 독특한 광학적, 자기적 성질을 가지고 있어 첨단 산업 분야에서 원 소별로 소수요 다품종의 첨가제로서 많이 사용된다. 광학 유리/섬유, 촉매제, 영구자석, 레이저, 형광체, 원자로 제어 소재 등 첨단 산업과 고기술 산업에 집중되어 사용되고 있

*Corresponding Author: Jae-Woo Ahn [Tel: +82-31-539-1982, E-mail: jwahn@daejin.ac.kr] Copyright (c) The Korean Institute of Metals and Materials
으며, 또한 최근에는 하이브리드 자동차나 풍력 발전 등의 녹색 기술 분야에서도 그 활용도가 높아지고 있어 희토류 자원의 확보와 정제/응용 기술 개발이 필요하다. 국내에서 는 희토류 광산에서 생산이 이루어지지 않고 부족한 정제 기술 등의 한계로 자력 생산이 불가능하여 국내 수요량의 대부분을 일본과 프랑스에서 수입하고 있고, 중간 화합물과 자석 완성품 형태로 수입에 의존하고 있다 [1-3,17]. 희토류 에 대한 수요가 증가함에 따라 희토류를 분리 정제하기 위 해 금속 열 환원법, 이온교환 크로마토그래피, 용매추출 등 의 많은 연구가 진행되고 있으며, 그 중 용매추출법은 선택 성이 우수하여 분리 효과가 높고 용매의 재사용이 용이하 며 저온 반응으로 에너지 소모가 적어 많이 사용되고 있다 희토류 분리 추출에는 $\mathrm{D}_{2} \mathrm{EHPA}, \mathrm{PC} 88 \mathrm{~A}$, Cyanex 272 등을 추출제로 사용한 연구 결과가 많이 보고되어 있지만 
[16], 아직까지 분리계수가 낮아 상호 분리에 있어 많은 추 출단, 세정단을 필요로 하는 문제점이 있다 [4]. 이들 추출 제의 분자구조는 그림 1 에 나타내었으며, 분자 구조에 따라 수소이온에 대한 해리도가 달라지며, $\mathrm{D}_{2} \mathrm{EHPA}$ 는 해리상수 $\mathrm{pK}_{\mathrm{a}}$ 3.24, $\mathrm{PC} 88 \mathrm{~A}$ 는 $\mathrm{pK}_{\mathrm{a}} 4.51$ 그리고 Cyanex 272는 $\mathrm{pK}_{\mathrm{a}}$ 6.37 의 값을 가진다. 추출 능력은 추출제의 해리상수 $\mathrm{pK}_{\mathrm{a}}$ 값에 의존하고, 분리성은 Cyanex $272>\mathrm{PC} 88 \mathrm{~A}>$ $\mathrm{D}_{2} \mathrm{EHPA}$ 순으로 우수하다 $[5,6] \cdot \mathrm{pK}_{\mathrm{a}}$ 값이 가장 큰 Cyanex 272 의 경우 희토류 원소에 대한 선택 분리성은 우수하지만, 추출 효율은 낮고 가격이 고가라는 단점이 있다. 이러한 특 성을 개선하기 위하여 Cyanex 272에 Alamine 336 및 TOA(Trioctylamine), TBP(Tri-butyl-phosphate)를 혼합하여 추출제로 사용한 연구가 보고되어 있으나, 혼합 추출제를 사용할 경우 추출 능력은 개선되지만 분리성은 다소 감소 하는 것으로 나타났다 [7,8]. 반면, 실제 현장에서 사용되고 있는 $\mathrm{PC} 88 \mathrm{~A}$ 는 추출 효율은 높지만 상대적으로 분리성이 낮아 상호 분리에 어려움이 있어 분리성 개선이 필요하다 [9,10]. 이러한 현상을 개선하기 위해 PC88A와 Cyanex 272의 혼합추출제로 개발된 Cyanex 572는 분리성과 추출 효율을 일부 개선하여, 제3상 조절제 첨가 없이 우수한 상 분리 특성을 보인다. $\mathrm{PC} 888 \mathrm{~A}$ 가 낮은 $\mathrm{pH}$ 영역에서 추출이 일어나기 때문에 탈거 시에 고농도의 산(acid)이 필요하다 는 문제점이 있지만, Cyanex 572를 사용할 경우 0.5 정도 높은 $\mathrm{pH}$ 영역에서 추출되기 때문에 탈거 시 산의 농도가 $\mathrm{PC} 88 \mathrm{~A}$ 보다 $30 \%$ 정도 낮다는 장점이 있다 [11,12]. 본 저 자들의 이전 연구에서 Cyanex 572를 사용하여 $\mathrm{La}, \mathrm{Ce}$, $\mathrm{Pr}, \mathrm{Nd}, \mathrm{Sm}$ 에 대하여 단일 성분 용액에서 추출 및 탈거 특성에 대한 연구를 소개한 바 있다 $[12,13]$. 기존에 발표 된 논문들 대부분은 2성분계 분리에 초점을 두었으나, 실제 희토류 광석 침출액으로부터 희토류 분리를 위해서는 다성 분 혼합 용액에서 희토류 성분들의 상호 추출 특성 등을 고려한 그룹별 분리에 대한 연구가 필요하다고 할 수 있다.

따라서 본 연구에서는 다성분 경희토 혼합용액에서 PC88A 및 Cyanex 572를 사용하여 각 원소들의 추출 거동 에 대해 조사하고, $[\mathrm{La}, \mathrm{Ce}] /[\mathrm{Pr}, \mathrm{Nd}],[\mathrm{La}] /[\mathrm{Pr}, \mathrm{Nd}, \mathrm{Sm}]$ 및 $[\mathrm{Pr}, \mathrm{Nd}] /[\mathrm{Sm}]$ 그리고 $[\mathrm{Ce}] /[\mathrm{Pr}, \mathrm{Nd}]$ 의 그룹 간 분리 특 성을 비교 하여 향후 분리공정 개발에 대한 기초 자료를 마 련하고자 하였다.

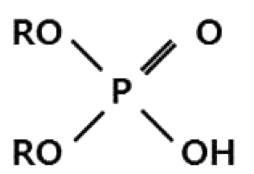

(a) $\mathrm{D}_{2} \mathrm{EHPA}$

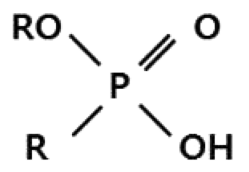

(b) $\mathrm{PC} 88 \mathrm{~A}$

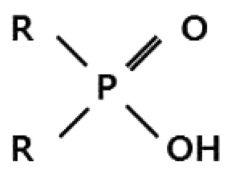

(c) Cyanex 272
Fig. 1. Molecule structures of extractants.

\section{2. 실험방법}

본 연구에서는 각각의 희토류(III) 염화물 시약을 사용 하여, $0.1 \mathrm{M}$ 염산에 희토류 원소를 $0.01 \mathrm{M}$ 씩 용해시켜 혼합 용액을 제조하여 수용액상으로 사용하였으며, 용액 의 조성은 표 1 과 같다. 추출제로는 PC88A(2-ethylhexyl phosphonicacid mono-2-ethylhexyl ester, Daihachi Chemical.), Cyanex 572(2,4,4-Trimethyl-1-pentene, Cytec Inc.)를 사용하였고, 희석제로는 Exxol D80(Exxon mobil chem.)을 사용하여 추출제의 농도를 조절하여 유기상을 제조 하였다. 추출 반응 시 $\mathrm{pH}$ 조절에는 $10 \mathrm{M} \mathrm{NaOH}, 5 \mathrm{M} \mathrm{HCl}$ 을 사용하였다. 상향식 교반 방식에 의해 수용액상과 유기상 을 상비(phase ratio, $\mathrm{A} / \mathrm{O}$ ) 1.0으로 혼합하여 $\mathrm{pH}$ 를 조절하고 10 분간 교반 후, 분액 여두에 옮겨 20 분 간 정치시켜 수상에 서 샘플을 채취하였다. 수용액상의 희토성분의 농도는 유도 결합 플라르마 분광기(inductively coupled plasma-optical emission spectometer, ICP-OES, iCAP 6500DUV)를 사용 하여 분석하였고, 샘플 분석 후 각 성분의 추출률(Extraction percentage, E), 분배계수(Distribution coefficients, D) 및 두 성분의 분리성의 척도를 나타내는 분리계수(Separation factor, $\beta$ )는 다음 식 (1), (2), (3)에 의해 계산하였다.

$\mathrm{E}(\%)=\frac{\text { 추출 후 유기상의 금속 농도 }}{\text { 초기 수용액상의 금속 농도 }} \times 100$

$\mathrm{D}=\frac{\text { 추출 후 유기상중의 금속 농도 }}{\text { 추출 후 수용액상의 금속 농도 }}$

$\beta \quad=\frac{D_{A}}{D_{B}}$

Table 1. Composition of synthetic solution used in study.

\begin{tabular}{ccccccc}
\hline & $\mathrm{La}$ & $\mathrm{Ce}$ & $\mathrm{Pr}$ & $\mathrm{Nd}$ & $\mathrm{Sm}$ & $\mathrm{HCl}$ \\
\hline Unit: $\mathrm{M}$ & 0.01 & 0.01 & 0.01 & 0.01 & 0.01 & $0.1 \mathrm{M}$ \\
\hline Unit: $\mathrm{ppm}$ & $1,389.1$ & $1,401.2$ & $1,409.1$ & $1,442.4$ & $1,503.6$ & \\
\hline
\end{tabular}




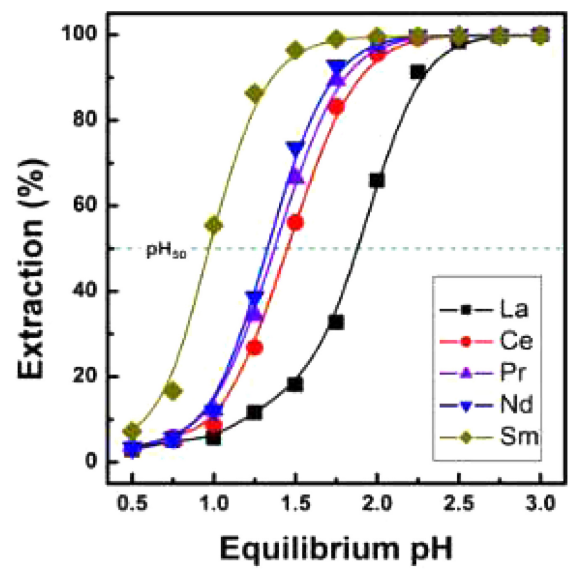

(a) $0.6 \mathrm{M} \mathrm{PC} 88 \mathrm{~A}$

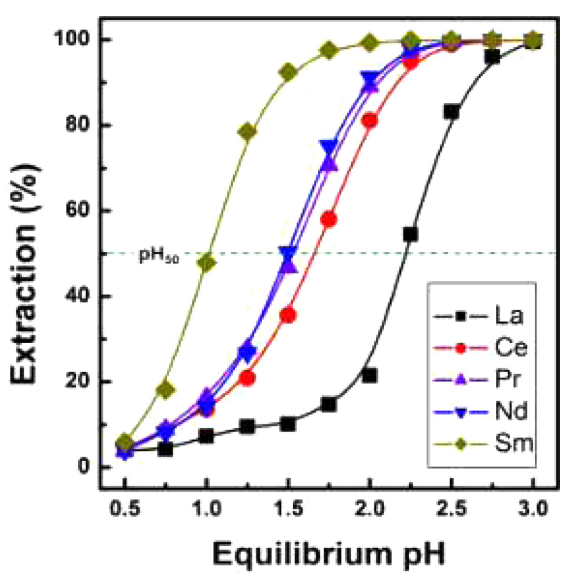

(b) 0.6 M Cyanex 572

Fig. 2. Effect of equilibrium $\mathrm{pH}$ on the extraction of Light care earth elements (LREEs) in mixed solutions (A/O: $1.0,25^{\circ} \mathrm{C}$ ).

여기서 $\mathrm{D}_{\mathrm{A}}$ 및 $\mathrm{D}_{\mathrm{B}}$ 는 희토류 원소 $\mathrm{A}$ 및 $\mathrm{B}$ 의 분배계수 이다.

\section{3. 실험 결과 및 고찰}

\section{1. 경희토 혼합용액에서 PC88A와 Cyanex 572에} 의한 $\mathrm{La}, \mathrm{Ce}, \mathrm{Pr}, \mathrm{Nd}, \mathrm{Sm}$ 의 추출 거동 비교

PC88A와 Cyanex 572에 의한 희토류 원소의 추출 반응 식은 다음 식 (4)과 같이 용액의 $\mathrm{pH}$ 에 민감하다는 것을 알 수 있으며, 분배계수 $\mathrm{D}$ 와 $\mathrm{pH}$ 와의 관계식은 식 (5)-(8) 와 같이 유도할 수 있다. 이때, $\mathrm{REE}^{3+}$ 는 희토류 이온, $\mathrm{REEA}_{3}$ 는 희토류의 추출종, $\mathrm{HA}$ 는 추출제이고, $\mathrm{K}$ 는 평형상 수이며, 식 (8)에서 $\mathrm{pH}$ 가 증가할수록 분배계수가 증가하며 추출제의 초기 농도가 증가할수록 $\log \mathrm{D}$ 와 $\mathrm{pH}$ 와의 관계에 서 그래프의 기울기가 3 에 가까워진다 [15].

$$
\begin{aligned}
& \operatorname{REE}^{3+}{ }_{\text {(aq.) }}+3 \mathrm{HA}_{\text {(org.) }} \rightarrow \operatorname{REEA}_{3 \text { (org.) }}+3 \mathrm{H}^{+} \text {(aq.) } \\
& \mathrm{K}=\left(\left[\operatorname{REEA}_{3(\text { org. })}\right] \times\left[\mathrm{H}_{\text {(aq.) })}^{+}\right]^{3}\right) /\left(\left[\operatorname{REE}^{3+}{ }_{(\text {aq. })}\right] \times\left[\mathrm{HA}_{(\text {org. })}\right]^{3}\right)
\end{aligned}
$$

$\mathrm{K}=\mathrm{D} \times\left[\mathrm{H}_{(\mathrm{aq} .)}^{+}\right]^{3} /\left[\mathrm{HA}_{(\mathrm{org})}\right]^{3}, \mathrm{D}=\mathrm{K} \times\left[\mathrm{HA}_{(\text {org. })}\right]^{3} /\left[\mathrm{H}_{(\mathrm{aq} .)}^{+}\right]^{3}$ (6)

$$
\begin{aligned}
\log \mathrm{D} & =\log \mathrm{K}+3 \log \left[\mathrm{HA}_{\text {(org.) }}\right]-3 \log \left[\mathrm{H}^{+} \text {(aq) }\right] \\
& =\log \mathrm{K}+3 \log \left[\mathrm{HA}_{\text {(org.) }}\right]+3 \mathrm{pH}
\end{aligned}
$$

$\log \mathrm{D}=3\left(\mathrm{pH}+\log \left[\mathrm{HA}_{\text {(org. })}\right]\right)+\log \mathrm{K}$

5 성분계 혼합용액에서 추출제로 $0.6 \mathrm{M} \mathrm{PC} 88 \mathrm{~A}$ 와 $0.6 \mathrm{M}$ Cyanex 572를 사용하여 $\mathrm{La}, \mathrm{Ce}, \mathrm{Pr}, \mathrm{Nd}, \mathrm{Sm}$ 에 대한 추
Table 2. Values of $\mathrm{pH}_{50}$ in mixed solutions.

\begin{tabular}{cccccc}
\hline & $\mathrm{La}$ & $\mathrm{Ce}$ & $\mathrm{Pr}$ & $\mathrm{Nd}$ & $\mathrm{Sm}$ \\
\hline $0.6 \mathrm{M}$ PC88A & 1.88 & 1.46 & 1.38 & 1.33 & 0.97 \\
\hline 0.6 M Cyanex 572 & 2.22 & 1.66 & 1.55 & 1.50 & 1.02 \\
\hline
\end{tabular}

출 거동을 비교하였다. 그 결과를 그림 2에 나타내었으며 두 추출제 모두 $\mathrm{pH}$ 가 증가함에 따라 추출률이 증가하였다. 그림 (a), (b)에서 PC88A를 사용하였을 경우 Cyanex 572 에 비해 더 낮은 $\mathrm{pH}$ 에서 추출되었고, $\mathrm{pH}$ 증가에 따른 추출률 증가폭이 더 컸다. 표 2에 각 성분이 $50 \%$ 추출 되는 $\mathrm{pH}\left(\mathrm{pH}_{50}\right)$ 를 나타내었는데, Cyanex 572를 사용하여 추출하였을 경우 $\mathrm{pH}_{50}$ 값이 $0.05 \sim 0.34$ 정도 더 높았다. $\mathrm{PC} 88 \mathrm{~A}$ 의 경우 $\mathrm{La}$ 과 $\mathrm{Sm}$ 의 $\mathrm{pH}_{50}$ 값의 차이가 0.91 인 반면, Cyanex 572는 1.20 으로 조금 더 넓은 $\mathrm{pH}$ 범위에 서 추출이 일어나는 것을 알 수 있다. 따라서 인접 원소 간 $\mathrm{pH}_{50}$ 값의 차이가 큰 Cyanex 572가 경희토류 원소 별 분리 시에 유리할 것으로 사료된다.

\section{2. $\mathrm{PC} 88 \mathrm{~A}$ 와 Cyanex 572 에 의한 2성분계 $(\mathrm{Ce} /$ $\mathrm{La}, \mathrm{Pr} / \mathrm{Ce}, \mathrm{Nd} / \mathrm{Pr}, \mathrm{Sm} / \mathrm{Nd}$ ) 분리성 비교}

5성분 혼합 용액에서 $0.6 \mathrm{M} \mathrm{PC} 88 \mathrm{~A}$ 와 $0.6 \mathrm{M}$ Cyanex 572 를 사용하여 추출 후 $\mathrm{pH}$ 에 따른 분배계수에 상용로그 를 취하여 $\mathrm{pH}$ 와 분배계수와의 관계를 그림 3 의 (a), (b)에 각각 나타내었다. 두 추출제 모두 원소별 기울기 차이가 크지 않았으며, $\mathrm{PC} 88 \mathrm{~A}$ 를 사용하였을 경우 그래프의 평균 기울기는 2.61이고, Cyanex 572의 경우는 평균 기울기가 2.09 를 나타내고 있다. 본 연구에서는 희토류 이온의 농도 에 비해 초기 추출제의 농도가 충분히 높지 않아 $\mathrm{pH}$ 에 


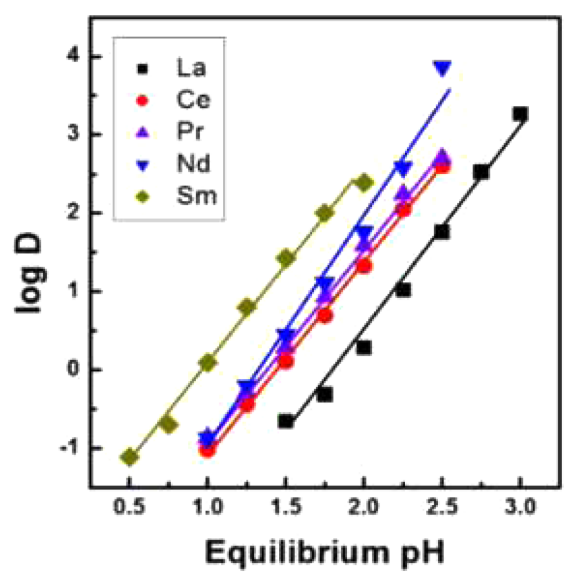

(a) $0.6 \mathrm{M}$ PC $88 \mathrm{~A}$

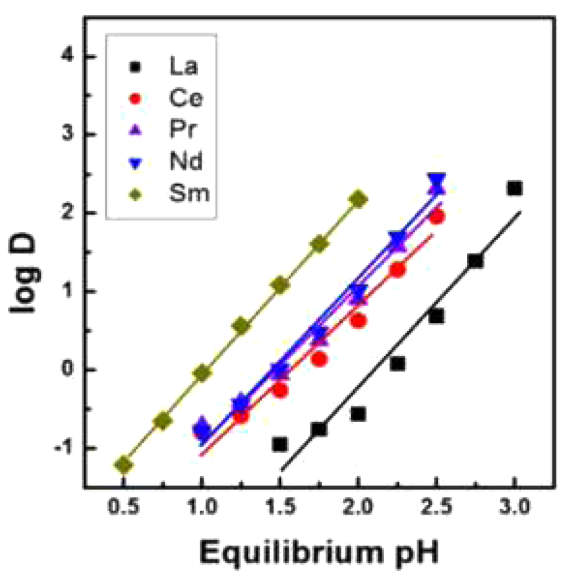

(b) 0.6 M Cyanex 572

Fig. 3. Plot of $\log \mathrm{D}$ vs. equilibrium $\mathrm{pH}$ for distribution coefficient of LREEs in mixed solutions (A/O: 1.0, $\left.25^{\circ} \mathrm{C}\right)$.

Table 3. Separation factor of two adjacent LREEs (A/O: $\left.1.0,25^{\circ} \mathrm{C}\right)$.

\begin{tabular}{|c|c|c|c|c|c|c|c|c|}
\hline \multirow[b]{2}{*}{$\mathrm{pH}$} & \multicolumn{2}{|c|}{$\beta_{\mathrm{Ce} / \mathrm{La}}$} & \multicolumn{2}{|c|}{$\beta_{\mathrm{Pr} / \mathrm{Ce}}$} & \multicolumn{2}{|c|}{$\beta_{\mathrm{Nd} / \mathrm{Pr}}$} & \multicolumn{2}{|c|}{$\beta_{\mathrm{Sm} / \mathrm{Nd}}$} \\
\hline & $\begin{array}{r}0.6 \mathrm{M} \\
\text { PC } 88 \mathrm{~A}\end{array}$ & $\begin{array}{c}0.6 \mathrm{M} \\
\text { Cyanex } \\
572\end{array}$ & $\begin{array}{r}0.6 \mathrm{M} \\
\text { PC } 88 \mathrm{~A}\end{array}$ & $\begin{array}{c}0.6 \mathrm{M} \\
\text { Cyanex } \\
572\end{array}$ & $\begin{array}{r}0.6 \mathrm{M} \\
\text { PC88A }\end{array}$ & $\begin{array}{c}0.6 \mathrm{M} \\
\text { Cyanex } \\
572\end{array}$ & $\begin{array}{r}0.6 \mathrm{M} \\
\mathrm{PC} 88 \mathrm{~A}\end{array}$ & $\begin{array}{c}0.6 \mathrm{M} \\
\text { Cyanex } \\
572\end{array}$ \\
\hline 1.00 & 1.60 & 2.01 & 1.44 & 1.25 & 0.98 & 0.84 & 9.13 & 5.58 \\
\hline 1.25 & 2.79 & 2.52 & 1.43 & 1.46 & 1.20 & 0.94 & 10.06 & 10.06 \\
\hline 1.50 & 5.78 & 4.92 & 1.55 & 1.59 & 1.41 & 1.15 & 9.59 & 12.13 \\
\hline 1.75 & 10.19 & 8.04 & 1.71 & 1.74 & 1.52 & 1.26 & 7.88 & 13.31 \\
\hline 2.00 & 10.93 & 15.77 & 1.82 & 1.90 & 1.50 & 1.29 & 4.26 & 14.33 \\
\hline 2.25 & 10.70 & 16.01 & 1.56 & 1.99 & 2.19 & 1.31 & 0.70 & 18.27 \\
\hline 2.50 & 6.98 & 18.48 & 1.26 & 2.22 & 14.81 & 1.34 & 0.04 & 8.86 \\
\hline
\end{tabular}

따른 분배계수 값이 작아져 이론적 기울기는 3 에 못 미쳤 으나, 본 저자의 이전 연구에서 추출제의 농도가 증가함에 따라 기울기가 3에 가까워짐을 알 수 있었으며, 따라서 Cyanex 572에 의한 희토류 추출 시에 식 (4)의 추출반응식 을 따르는 것을 알 수 있다 [12]. 한편, 표 3에는 인접원소 간의 분리계수를 나타내었는데, Cyanex 572를 사용하였을 경우, $\mathrm{La}$ 과 $\mathrm{Ce}, \mathrm{Nd}$ 와 $\mathrm{Sm}$ 사이의 분리계수 값의 차이가 5 이상 증가하여 PC88A보다 분리성이 개선됨을 알 수 있었 고, $\mathrm{Ce}$ 과 $\mathrm{Pr}, \mathrm{Pr}$ 과 $\mathrm{Nd}$ 의 분리계수는 큰 차이는 없었다.

\section{3 비누화율에 따른 PC88A와 Cyanex 572 추출} 거동

PC88A나 Cyanex 572와 같은 양이온 추출제를 사용하 여 희토류 분리 시에 다단 조형추출기(mixer-settler)를 사 용하여 연속 공정 조업을 하는데 이때, 공정 중 수상의 $\mathrm{pH}$ 가 감소하여 추출 구동력이 감소되는 현상이 발생될 수
있다 [14]. 이러한 수용액상의 $\mathrm{pH}$ 의 급격한 저하를 방지하 기 위해서 추출제를 사전에 비누화하여 사용한다. 추출제 의 비누화 반응식을 식 (9)에 나타내었고, 비누화 추출제에 의한 희토류 추출반응식을 식 (10)에 나타내었다.

$$
\begin{aligned}
& \mathrm{HA}_{\text {(org.) }}+\mathrm{NaOH}_{\text {(aq.) }} \rightarrow \mathrm{NaA}_{\text {(org.) }}+\mathrm{H}_{2} \mathrm{O}_{\text {(aq.) }} \\
& \mathrm{REE}^{3+}{ }_{\text {(aq.) }}+3 \mathrm{NaA}_{\text {(org.) }} \rightarrow \mathrm{REEA}_{3 \text { (org.) }}+3 \mathrm{Na}^{+}{ }_{\text {(aq.) }}
\end{aligned}
$$

일반적으로 추출제 비누화율이 낮을 경우에는 $\mathrm{pH}$ 저하 현상을 방지하기 위한 효과가 낮고, 비누화율 높은 경우에 는 비누화 시 사용되는 $\mathrm{NaOH}$ 에 의해 에멀젼상이 생성될 수 있어 추출 효율을 감소시킬 수 있다. 본 연구에서는 $\mathrm{NaOH}$ 를 사용하여 $0.6 \mathrm{M}$ PC88A와 0.6 M Cyanex 572 를 $5 ~ 50 \%$ 비누화하여, 평형 $\mathrm{pH}$ 를 1.5 에서 비누화율에 따른 $\mathrm{La}, \mathrm{Ce}, \mathrm{Pr}, \mathrm{Nd}, \mathrm{Sm}$ 추출 거동을 살펴보았다. 그림 4 의 (a)에서 PC $88 \mathrm{~A}$ 의 경우 비누화를 하지 않았을 경우보다 비 


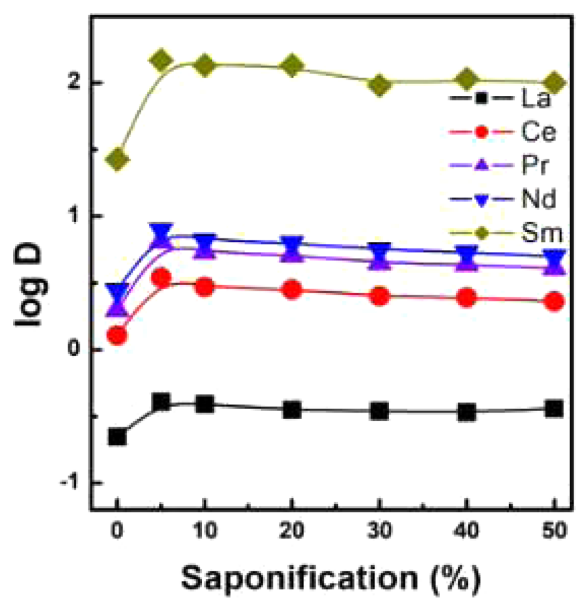

(a) $0.6 \mathrm{M} \mathrm{PC} 88 \mathrm{~A}$

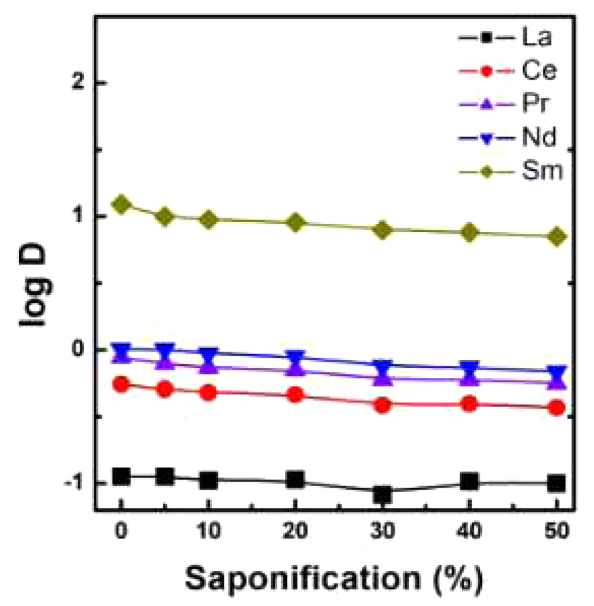

(b) 0.6 M Cyanex 572

Fig. 4. Effect of saponification percentage on the extraction of LREEs in mixed solutions (equilibrium pH 1.5, A/O: $1.0,25^{\circ} \mathrm{C}$ ).

Table 4. Separation factor of two adjacent LREEs (equilibrium $\mathrm{pH} 1.5$, A/O: $1.0,25^{\circ} \mathrm{C}$ ).

\begin{tabular}{cccccccccc}
\hline \multirow{2}{*}{$\begin{array}{c}\text { Saponi } \\
\text { fication } \\
(\%)\end{array}$} & \multicolumn{2}{c}{$\beta_{\mathrm{Ce} / \mathrm{La}}$} & \multicolumn{3}{c}{$\beta_{\mathrm{Pr} / \mathrm{Ce}}$} & \multicolumn{3}{c}{$\beta_{\mathrm{Nd} / \mathrm{Pr}}$} & \multicolumn{2}{c}{$\beta_{\mathrm{Sm} / \mathrm{Nd}}$} \\
\cline { 2 - 10 } & $0.6 \mathrm{M}$ & $0.6 \mathrm{M}$ & $0.6 \mathrm{M}$ & $0.6 \mathrm{M}$ & $0.6 \mathrm{M}$ & $0.6 \mathrm{M}$ & $0.6 \mathrm{M}$ & Cyanex \\
& PC88A & $\begin{array}{c}\text { Cyanex } \\
572\end{array}$ & PC88A & $\begin{array}{c}\text { Cyanex } \\
572\end{array}$ & PC88A & $\begin{array}{c}\text { Cyanex } \\
572\end{array}$ & $\begin{array}{c}\text { PC88A } \\
572\end{array}$ \\
\hline 0 & 5.78 & 4.92 & 1.55 & 1.59 & 1.41 & 1.15 & 9.59 & 12.14 \\
\hline 5 & 8.39 & 4.52 & 1.86 & 1.55 & 1.23 & 1.28 & 18.91 & 9.89 \\
\hline 10 & 7.54 & 4.56 & 1.85 & 1.54 & 1.23 & 1.27 & 20.43 & 10.13 \\
\hline 20 & 7.83 & 4.31 & 1.83 & 1.53 & 1.24 & 1.27 & 21.58 & 10.11 \\
\hline 30 & 7.23 & 4.70 & 1.81 & 1.56 & 1.24 & 1.25 & 17.07 & 10.53 \\
\hline 40 & 7.19 & 3.82 & 1.79 & 1.53 & 1.23 & 1.24 & 19.56 & 10.25 \\
\hline 50 & 6.44 & 3.70 & 1.77 & 1.53 & 1.23 & 1.22 & 19.89 & 10.29 \\
\hline
\end{tabular}

누화를 하였을 경우 분배계수가 증가하였으며, 비누화율이 증가하여도 분배계수 값의 변화는 크지 않았다. 또한, 그림 4의 (b)에서 Cyanex572도 비누화를 하지 않았을 경우와 비누화를 하였을 경우 분배계수의 큰 차이는 없었으며, 비 누화율이 증가하여도 분배계수에 미치는 영향은 미미하였 다. 본 연구 결과, 두 추출제의 경우 비누화율은 5 100\% 가 적정함을 알 수 있다. 비누화율에 따른 인접 원소간 분 리계수를 표 4에 나타내었는데, Cyanex 572의 경우 비누 화율이 분리계수에 미치는 영향이 거의 없었다. 반면, $\mathrm{PC} 88 \mathrm{~A}$ 의 경우에는 비누화 전보다 비누화 후 분리계수가 증가하였으며 특히 $\mathrm{Nd}$ 와 $\mathrm{Sm}$ 의 사이의 분리계수가 8 이상 크게 증가하여 분리성 개선 효과를 보였다.

\section{4. 그룹 간 분리특성 비교}

5 성분 $(\mathrm{La}, \mathrm{Ce}, \mathrm{Pr}, \mathrm{Nd}, \mathrm{Sm})$ 혼합용액에서 다음과 같은
4그룹 $([\mathrm{La}, \mathrm{Ce}] /[\mathrm{Pr}, \mathrm{Nd}],[\mathrm{La}] /[\mathrm{Pr}, \mathrm{Nd}, \mathrm{Sm}],[\mathrm{Pr}, \mathrm{Nd}] /$ $[\mathrm{Sm}],[\mathrm{Ce}] /[\mathrm{Pr}, \mathrm{Nd}])$ 으로 나누어 그룹 간 분리계수를 조사 하였다. 이 경우 각 원소의 농도는 $0.01 \mathrm{M}$ 이었으며, 평형 $\mathrm{pH}$ 변화 결과로부터 두 종류의 추출제의 그룹 간 분리특 성을 고찰하였다.

\subsection{1 [ $\mathrm{La}, \mathrm{Ce}] /[\mathrm{Pr}, \mathrm{Nd}]$ 그룹 간 분리}

경희토 그룹 내에서 중간 분리로 경희토를 분류하는 $[\mathrm{La}, \mathrm{Ce}]$ 과 $[\mathrm{Pr}, \mathrm{Nd}]$ 그룹 간 분리 가능성 여부를 조사하 였다. $0.6 \mathrm{M} \mathrm{PC} 88 \mathrm{~A}$ 와 $0.6 \mathrm{M}$ Cyanex 572를 사용하여 평 형 $\mathrm{pH}$ 에 따른 추출 거동을 살펴보았으며, 평형 $\mathrm{pH}$ 에 따 른 각 성분의 분배계수를 그림 5의 (a), (b)에 나타내었다. 각 원소들의 분배계수에 상용로그 취하여 $\mathrm{pH}$ 와 $\log \mathrm{D}$ 의 관계로 나타내었으며, 네 성분 모두 $\mathrm{pH}$ 증가에 따라 직선 적으로 $\log \mathrm{D}$ 값이 증가하는 것을 알 수 있었다. 그룹 내 


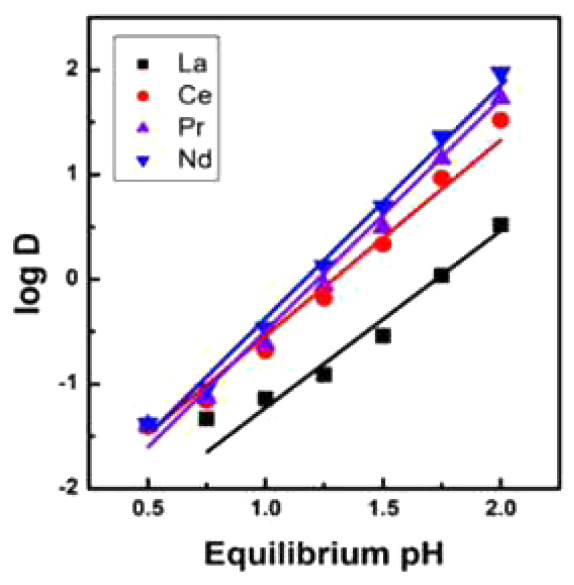

(a) $0.6 \mathrm{M}$ PC88A

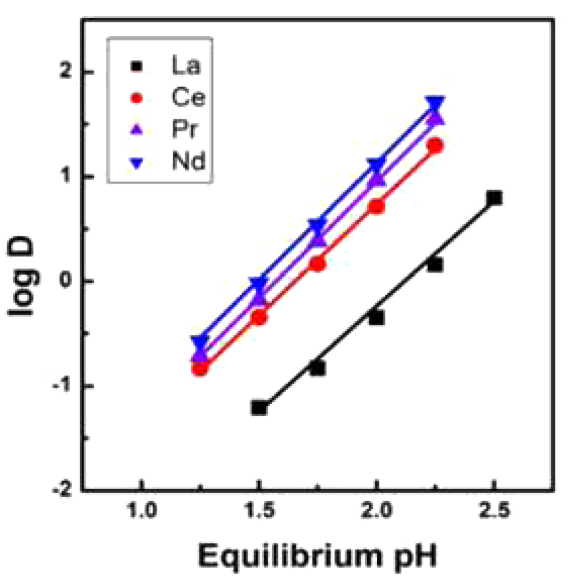

(b) 0.6 M Cyanex 572

Fig. 5. Plot of $\log \mathrm{D}$ vs. equilibrium for distribution coefficient of $\mathrm{La}, \mathrm{Ce}, \mathrm{Pr}, \mathrm{Nd}\left(\mathrm{A} / \mathrm{O}: 1.0,25^{\circ} \mathrm{C}\right)$.

Table 5. Separation factor between $[\mathrm{La}, \mathrm{Ce}]$ and $[\mathrm{Pr}, \mathrm{Nd}]$ group (A/O: $\left.1.0,25^{\circ} \mathrm{C}\right)$.

\begin{tabular}{|c|c|c|c|c|c|c|c|c|c|c|}
\hline & $\mathrm{pH}$ & 0.50 & 0.75 & 1.00 & 1.25 & 1.50 & 1.75 & 2.00 & 2.25 & 2.50 \\
\hline \multirow{2}{*}{$\beta_{\mathrm{Pr} / \mathrm{Ce}}$} & $0.6 \mathrm{M} \mathrm{PC} 88 \mathrm{~A}$ & 1.03 & 1.06 & 1.17 & 1.32 & 1.45 & 1.53 & 1.62 & - & - \\
\hline & 0.6 M Cyanex 572 & - & - & 1.25 & 1.32 & 1.47 & 1.66 & 1.79 & 1.80 & 1.67 \\
\hline
\end{tabular}

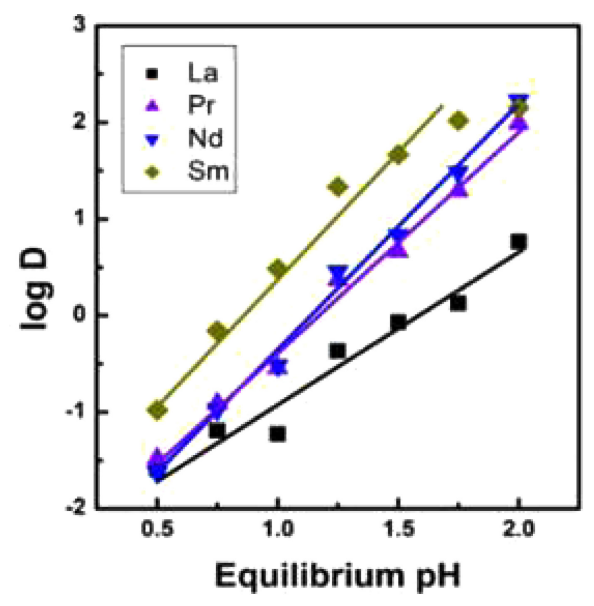

(a) $0.6 \mathrm{M} \mathrm{PC} 88 \mathrm{~A}$

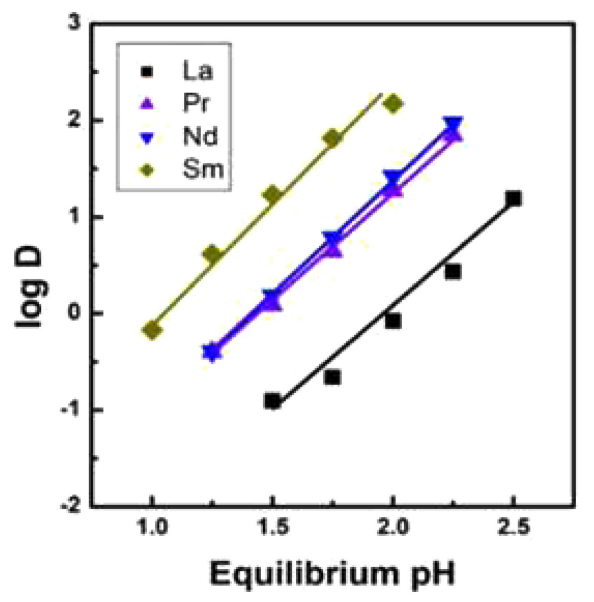

(b) 0.6 M Cyanex 572

Fig. 6. Plot of $\log \mathrm{D}$ vs. equilibrium $\mathrm{pH}$ for distribution coefficient of $\mathrm{La}, \mathrm{Pr}, \mathrm{Nd}, \mathrm{Sm}\left(\mathrm{A} / \mathrm{O}: 1.0,25^{\circ} \mathrm{C}\right)$.

에서 분리성을 알아보기 위해 $\mathrm{Ce}$ 과 $\operatorname{Pr}$ 사이의 분리계수를 표 5에 나타내었으며, $\mathrm{PC} 88 \mathrm{~A}$ 의 경우 $\mathrm{pH} 2.0$ 에서 1.62 의 가장 높은 분리계수를 보였으나, Cyanex 572를 사용하였 을 경우 $\mathrm{pH} 2.25$ 에서 1.80 의 분리계수를 보여 Cyanex 572 가 0.18 정도 더 높아 분리성이 일부 개선됨을 확인할 수 있었다.

\subsection{2 [ $\mathrm{La}] /[\mathrm{Pr}, \mathrm{Nd}, \mathrm{Sm}]$ 그룹 간 분리}

[La]과 [ $\mathrm{Pr}, \mathrm{Nd}, \mathrm{Sm}]$ 그룹과의 분리성을 비교하기 위
해 평형 $\mathrm{pH}$ 에 따른 분배계수를 그림 6에 나타내었다. 그 림 6(a)의 $\mathrm{PC} 88 \mathrm{~A}$ 의 경우 $\mathrm{pH}$ 가 증가함에 따라 $\log \mathrm{D}$ 의 값이 직선적으로 증가하나 원자번호가 증가할수록 $\mathrm{pH}$ 와 $\log \mathrm{D}$ 의 관계에서 그래프의 기울기가 $\mathrm{La} 1.55$ 에서 $\mathrm{Sm}$ 2.46 으로 증가하였다. 반면, Cyanex 572는 $\mathrm{pH}$ 에 증가에 따라 $\log \mathrm{D}$ 의 값이 직선적으로 증가하였으며 원소들의 기울기 차이가 크지 않고 평균 2.28 의 기울기를 보였다. 그룹을 나누는 인접 원소인 $\mathrm{La}$ 과 $\operatorname{Pr}$ 사이의 분리계수를 표 6에 나타내었으며, $\mathrm{PC} 88 \mathrm{~A}$ 는 $\mathrm{pH} 2.0$ 에서 16.80 의 분 
Table 6. Separation factor between [La] and [Pr, Nd, Sm] group (A/O: $1.0,25^{\circ} \mathrm{C}$ ).

\begin{tabular}{cccccccccccc}
\hline & $\mathrm{pH}$ & 0.50 & 0.75 & 1.00 & 1.25 & 1.50 & 1.75 & 2.00 & 2.25 & 2.50 \\
\hline \multirow{2}{*}{$\beta_{\mathrm{Pr} / \mathrm{La}}$} & $0.6 \mathrm{M} \mathrm{PC88A}$ & 1.31 & 1.92 & 4.79 & 5.39 & 5.44 & 14.58 & 16.80 & - & - \\
\cline { 2 - 12 } & $0.6 \mathrm{M}$ Cyanex 572 & - & - & 40.57 & 5.02 & 9.80 & 20.22 & 22.39 & 25.69 & 16.80 \\
\hline
\end{tabular}

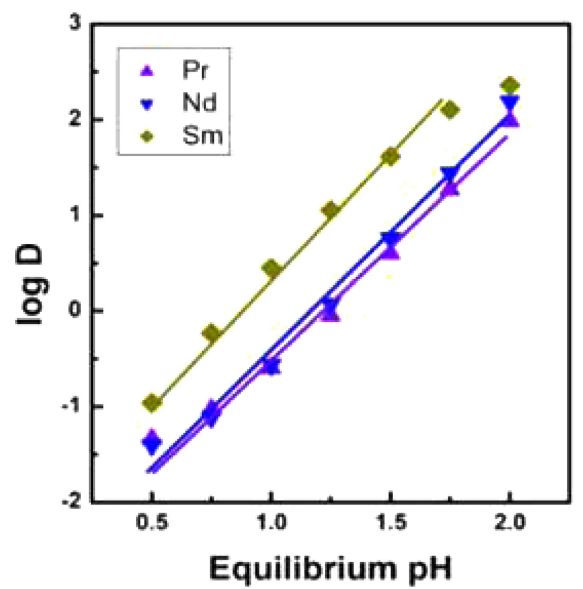

(a) $0.6 \mathrm{M} \mathrm{PC} 88 \mathrm{~A}$

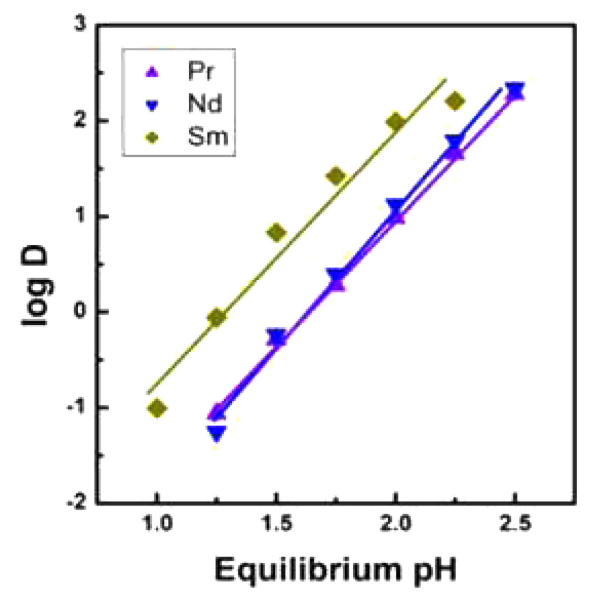

(b) $0.6 \mathrm{M}$ Cyanex 572

Fig. 7. Plot of $\log \mathrm{D}$ vs. equilibrium $\mathrm{pH}$ for distribution coefficient of $\mathrm{Pr}, \mathrm{Nd}, \mathrm{Sm}\left(\mathrm{A} / \mathrm{O}: 1.0,25^{\circ} \mathrm{C}\right)$.

Table 7. Separation factor between $[\mathrm{Pr}, \mathrm{Nd}]$ and $[\mathrm{Sm}]$ group (A/O: $\left.1.0,25^{\circ} \mathrm{C}\right)$.

\begin{tabular}{cccccccccccc}
\hline & $\mathrm{pH}$ & 0.50 & 0.75 & 1.00 & 1.25 & 1.50 & 1.75 & 2.00 & 2.25 & 2.50 \\
\hline \multirow{2}{*}{$\beta_{\mathrm{Sm} / \mathrm{Nd}}$} & $0.6 \mathrm{M} \mathrm{PC88A}$ & 2.76 & 7.56 & 10.37 & 9.51 & 7.21 & 4.58 & 1.47 & - & - \\
\cline { 2 - 30 } & 0.6 M Cyanex 572 & - & - & 8.71 & 15.62 & 11.72 & 10.62 & 7.31 & 0.88 \\
\hline
\end{tabular}

리계수를 보였고, Cyanex 572의 경우 $\mathrm{pH}$ 2.25에서 분 리계수 25.69로, 분리계수 값이 8.89 정도 크게 증가하였 다. 따라서 [La]과 $[\mathrm{Pr}, \mathrm{Nd}, \mathrm{Sm}]$ 그룹의 분리에서 $\mathrm{PC} 88 \mathrm{~A}$ 와 Cyanex 572 모두 16이상의 높은 분리계수를 보였으나 Cyanex 572를 사용하는 것이 분리 효과가 크 게 향상 되었다.

\subsection{3 [Pr, Nd]/[Sm] 그룹 간 분리}

$[\mathrm{Pr}, \mathrm{Nd}] /[\mathrm{Sm}]$ 그룹의 분리 특성을 고찰하기 위해 $0.6 \mathrm{M} \mathrm{PC} 88 \mathrm{~A}$ 와 Cyanex 572를 사용하여 평형 $\mathrm{pH}$ 에 따른 분배계수와 분리계수를 살펴보았으며, 평형 $\mathrm{pH}$ 와 $\log \mathrm{D}$ 의 관계를 그림 7(a), (b)에 나타내었다. 두 추출제 모두 $\mathrm{Pr}, \mathrm{Nd}, \mathrm{Sm}$ 은 평형 $\mathrm{pH}$ 에 따른 분배계수가 직선적 으로 증가하였으며, Cyanex572를 사용할 경우 분리하고 자 하는 $\mathrm{Pr}, \mathrm{Nd}$ 와 $\mathrm{Sm}$ 사이의 분배계수 차이가 더 큰 것을 알 수 있었다. $\mathrm{Nd}$ 와 $\mathrm{Sm}$ 사이의 분리계수를 표 7 에 나타내었으며, $\mathrm{PC} 88 \mathrm{~A}$ 의 경우 $\mathrm{pH}$ 0.75에서 1.25 사 이의 범위에서 7.56 에서 10.37 의 분리계수를 보인 반면,
Cyanex 572의 경우 $\mathrm{pH} 1.25$ 에서 1.75 사이의 범위에 서 10.62에서 15.62의 분리계수를 보였다. [Pr, Nd]/ [Sm] 그룹의 분리계수는 PC88A와 Cyanex 572 모두 10 이상의 분리계수를 보였고 Cyanex 572의 경우가 $\mathrm{PC} 88 \mathrm{~A}$ 보다 분리계수가 3 5 정도 더 높아 분리성이 개 선됨을 알 수 있었다.

\subsection{4 $[\mathrm{Ce}] /[\mathrm{Pr}, \mathrm{Nd}]$ 그룹 간 분리}

경희토 금속 중 $[\mathrm{Ce}]$ 과 $[\mathrm{Pr}, \mathrm{Nd}]$ 의 두 그룹 간 분리 가능성을 고찰하기 위해 평형 $\mathrm{pH}$ 에 따른 추출 거동을 살 펴보았다. 그림 8 에 $\mathrm{pH}$ 와 $\log \mathrm{D}$ 의 관계로 실험결과를 나 타내었으며, 그림 8(a)에서 $\mathrm{PC} 88 \mathrm{~A}$ 를 사용할 경우 $\mathrm{pH}$ 0.5 에서 1.75 까지 분배계수가 $\mathrm{pH}$ 에 따라 직선적으로 증가 하였으며, 그림 $8(\mathrm{~b})$ 에서 Cyanex 572의 경우 경우 $\mathrm{pH}$ 1.0 에서 2.25 까지 직선적으로 증가하였다. 한편, 그룹 간 분리에서 인접 원소인 $\mathrm{Nd}$ 와 $\mathrm{Sm}$ 에 대한 분리계수를 표 8 에 나타내었는데, $\mathrm{PC} 88 \mathrm{~A}$ 의 경우 $\mathrm{pH} 1.75$ 에서 1.94 의 분 리계수를 보인 반면, Cyanex 572를 사용하였을 경우 $\mathrm{pH}$ 


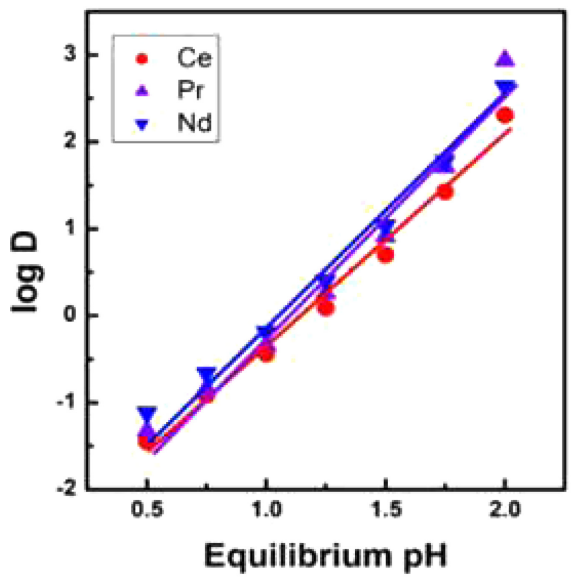

(a) $0.6 \mathrm{M} \mathrm{PC88A}$

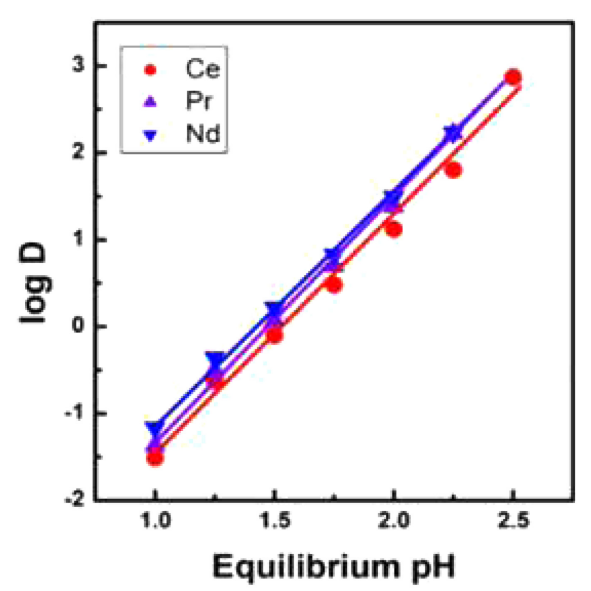

(b) 0.6 M Cyanex 572

Fig. 8. Plot of $\log \mathrm{D}$ vs. equilibrium $\mathrm{pH}$ for distribution coefficient of $\mathrm{Ce}, \mathrm{Pr}, \mathrm{Nd}\left(\mathrm{A} / \mathrm{O}: 1.0,25^{\circ} \mathrm{C}\right)$.

Table 8. Separation factor between $[\mathrm{Ce}]$ and $[\mathrm{Pr}, \mathrm{Nd}]$ group (A/O: $\left.1.0,25^{\circ} \mathrm{C}\right)$.

\begin{tabular}{cccccccccccc}
\hline & $\mathrm{pH}$ & 0.50 & 0.75 & 1.00 & 1.25 & 1.50 & 1.75 & 2.00 & 2.25 & 2.50 \\
\hline \multirow{2}{*}{$\beta_{\mathrm{Pr} / \mathrm{Ce}}$} & $0.6 \mathrm{M} \mathrm{PC} 88 \mathrm{~A}$ & 1.32 & 1.20 & 1.27 & 1.48 & 1.64 & 1.94 & - & - & - \\
\cline { 2 - 11 } & $0.6 \mathrm{M}$ Cyanex 572 & - & - & 1.39 & 1.32 & 1.49 & 1.66 & 1.83 & 2.63 & - \\
\hline
\end{tabular}

2.25 에서 2.63 의 가장 높은 분리계수를 보여 분리계수가 약 0.7 증가하였다. 따라서 [Ce]과 [Pr, Nd] 그룹 간 분 리에 있어서도 Cyanex 572를 사용하는 것이 분리성이 다 소 개선되는 것으로 보인다.

\section{4. 결 론}

본 연구에서는 염산계 경희토류 다성분 혼합 용액에서 $\mathrm{PC} 88 \mathrm{~A}$ 와 Cyanex 572를 사용하여 추출 거동과 경희토류 내에서 그룹 간 분리 특성을 비교하기 위한 실험을 실시하 여 다음과 같은 결론을 얻을 수 있었다.

1) 경희토류 5성분 혼합 용액에서 $0.6 \mathrm{M} \mathrm{PC88A}$ 를 사용 하였을 경우 $\mathrm{La}$ 과 $\mathrm{Sm}$ 의 $\mathrm{pH}_{50}$ 값의 차이가 0.91 인 반면 $0.6 \mathrm{M}$ Cyanex 572의 경우 1.20 으로 더 넓은 범위에서 추 출이 일어났다.

2) 5성분 혼합 용액에서 $\mathrm{pH}$ 가 증가함에 따라 분배계수 값이 직선적으로 증가하였다. $0.6 \mathrm{M} \mathrm{PC88A} \mathrm{보다} 0.6 \mathrm{M}$ Cyanex 572를 사용할 경우 분리계수가 더 높아 분리성 개선 효과를 보였다.

3) $\mathrm{PC} 88 \mathrm{~A}$ 와 Cyanex 572의 비누화율에 따른 $\mathrm{La}, \mathrm{Ce}$, $\mathrm{Pr}, \mathrm{Nd}, \mathrm{Sm}$ 추출 거동을 고찰한 결과, $\mathrm{PC} 88 \mathrm{~A}$ 는 비누화 시 분배계수가 증가하였으나, Cyanex 572는 큰 차이가 없
었다. 비누화율이 증가함에 따라 두 추출제 모두 분배계수 의 차이는 거의 없었다. $\mathrm{PC} 88 \mathrm{~A}$ 는 비누화시 분리계수가 일부 개선되는 효과를 보였으나, Cyanex 572의 경우 분리 계수의 개선 효과는 없었다.

4) 4 개 그룹군 $([\mathrm{La}, \mathrm{Ce}] /[\mathrm{Pr}, \mathrm{Nd}],[\mathrm{La}] /[\mathrm{Pr}, \mathrm{Nd}, \mathrm{Sm}]$, $[\mathrm{Pr}, \mathrm{Nd}] /[\mathrm{Sm}],[\mathrm{Ce}] /[\mathrm{Pr}, \mathrm{Nd}])$ 으로 나누어 그룹 간 분리 특성을 고찰한 결과 $[\mathrm{La}] /[\mathrm{Pr}, \mathrm{Nd}, \mathrm{Sm}],[\mathrm{Pr}, \mathrm{Nd}] /[\mathrm{Sm}]$ 그룹은 $\mathrm{PC} 88 \mathrm{~A}$ 보다 Cyanex 572를 사용하였을 경우 분리 계수가 3 8 정도 더 높아 분리성이 크게 개선 될 수 있 을 것으로 보이나 [La, $\mathrm{Ce}] /[\mathrm{Pr}, \mathrm{Nd}],[\mathrm{Ce}] /[\mathrm{Pr}, \mathrm{Nd}]$ 그룹 은 Cyanex 572에 의해 분리계수가 0.2 0.7 정도 소폭 상 승하였으나 분배계수가 차이가 크지 않아 그룹 간 분리가 용이하지 않을 것으로 보인다.

\section{감사의 글}

본 연구는 2018년 정부(과학기술정보통신부)의 재원으로 국가과학기술연구회 융합연구단사업(No. CRC-15-06$\mathrm{KIGAM}$ )의 지원을 받아 수행되었습니다.

\section{REFERENCES}

1. M. S. Lee, G. S. Lee, J. Y. Lee, S. D. Kim, and J. S. Kim, J. 
Kor. Inst. Met. \& Mater. 42, 835 (2004).

2. G. S. Lee, J. Y. Lee, S. D. Kim, J. S. Kim, and M. S. Lee, J. Korean Inst. Resour. Recycl. 13(4), 39 (2004).

3. J. H. Cho, H. S. Lee, C. H. Kim, and K. H. Shin, Korea Environment Institute 17-254, 1 (2013).

4. J. H. Park, H. S. Jeon, and M. S. Lee, J. Korean Inst. Resour. Recycl. 22(5), 35 (2013).

5. B. A. Moyer, Ion Exchange and Solvent Extraction: Volume 21, Supramolecular Aspects of Solvent Extraction, pp. 293, CRC Press (2013).

6. X. Wang, W. Li, S. Meng, and D. Li, J. Chem. Technol. Biotechnol. 81, 761 (2006).

7. M. S. Lee, Korea Patent 10-1643049 (2016).

8. J. S. Park, H. S. Jeon, and M. S. Lee, J. Korean Inst. Resour. Recycl. 23(2), 37 (2014).

9. M. S. Lee, G. S. Lee, J. Y. Lee, S. D. Kim, and J. S. Kim, J. Korean Inst. Resour. Recycl. 14(2), 33 (2005).

10. M. D. Soderstrom, T. McCallum, B. Jakovljevic, and A. J.
Quilodrán, COM 2014, Conf. of Metallurgists Proceedings (2014).

11. T. McCallum, M. Soderstrom, A. Quiloran, and B. Jakovljevic, ALTA 2014, Uranium-REE Proceeding (2014).

12. Y. C. Cho, M. S. Kang, J. W. Ahn, and J. Y. Lee, J Korean Inst. Resour Recycl. 25(6), 50 (2016).

13. Y. C. Cho, J. E. Lee, H. I. So, J. W. Ahn, H. I Kim, and J. Y. Lee, J Korean Inst. Resour Recycl. 26(4), 79 (2017).

14. M. S. Lee, J. Y. Lee, and J. S. Kim, J Korean Inst. Resour Recycl. 17(1), 12 (2008).

15. J. E. Quinn, K. H. Soldenhoff, G. W. Stevens, and N. A. Lengkeek, Hydrometallurgy 157, 298 (2015).

16. Y. Liu, H. S. Jeon, and M. S. Lee, Korean J. Met. Mater. 54, 592 (2016).

17. W. Jung, D. Kim, Y, J. Lee, Y. Oh, and W. Chung, Met. Mater. Int. 23, 385 (2017). 